\title{
A RARE FORM OF RETINO-CHOROIDITIS, POSSIBLY ASSOCIATED WITH PITUITARY DYSFUNCTION*
}

BY

\author{
W. G. LaWs \\ NOTTINGHAM
}

FIVE years ago the following case came under my observation.

H. D., a girl, 20 years of age, had recently noticed dimness of the left eye. The right vision was $6 / 5$, the left $6 / 60$.

Ophthalmoscopic examination showed :- $\mathrm{R}$, normal. $\mathrm{L}$, hazy disc with retinal oedema, most marked in the central region. No choroidal lesions were visible at this time, but they soon began to make their appearance, and five months after the first visit it was noted that the eye now showed an extensive area covered by patches of superficial choroido-retinitis, reaching almost as far as could be seen above, not quite so far in other directions. Central vision had improved to $6 / 6$, partly.

Three years after the first onset the right eye began to show retinal haze and misty vision; it went through an attack exactly like that of the left.

On the last occasion on which I saw the patient (October, 1920), right vision was $6 / 5$, partly, left $6 / 5$, nearly; the fundi had the appearance of a case of old specific choroido-retinitis, except that the optic discs showed no pallor and the retinal vessels no narrowing.

The patient to whom these notes refer was a healthy-looking girl, perhaps of rather nervous type, with a good family history, no personal history of illness of any moment, and leading a very normal healthy life. Careful examination by a consulting physician revealed no sign of disease; the Wassermann and tuberculin tests gave negative results. We had the advantage of repeated consultations with a well-known London ophthalmic surgeon, but he was unable to suggest any cause for the eye affection.

It cannot but strike one as extraordinary that a person apparently in perfect health should go through a definite and fairly severe inflammatory affection of each eye without any cause for it being discovered in any organ or function of the body. The only inference that can be drawn is that the search was not sufficiently exhaustive. The following cases seem to point out a direction in which further investigation might be fruitful.

Mrs. S., aged 30, after a normal confinement with her first child, discovered that she could not see with the left eye. She consulted an oculist, who found recent choroiditis of the central region, with some peripheral lesions of older date. The other eye was normal.

\footnotetext{
* Paper read at a Meeting of the Midland Ophthalmological Society, February 5, 1924.
} 
I saw her two and a half years later. She was five months advanced in her second pregnancy; in good health; the urine normal. She came because she was seeing spots before the right eye.

I found right vision 6/12, disc hazy and swollen, central region of retina oedematous, with two soft yellowish-grey foci beneath it ; some older patches (choroidal atrophy and pigmentation) were seen towards the periphery. Vision of left eye counting fingers at one foot. The choroid of this eye was deeply pigmented with sclerosed vessels showing up sharply on it; on this background there were masses of mossy retinal pigment. The disc was of good colour; the retinal vessels of normal size. Next day central vision of the right eye was counting fingers at four feet. After consultation with her doctor, terminating the pregnancy was decided on ; this was done the same night. A month later right vision was 6/12. Two years later the right eye showed marked sclerosis of choroidal vessels in the central region, with masses and rings of pigment, but central vision was $6 / 6$ partly. This condition has been maintained. No further pregnancy has occurred, and she has remained in good general health during the fifteen years which have elapsed since the attack.

W. L., aged 16, an overgrown lad with thick, heavy features and projecting brows. Right vision 6/18. Disc decidedly hazy, retinal veins full. Fundus studded with patches of superficial atrophy of choroid, most thickly grouped about disc and macula. Left vision $6 / 5$, fundus normal. Two months later the left eye was affected in the same way as the right; many of the patches of choroiditis were quite recent, soft, ill-defined, yellowish-white. Vision 6/36.

Some months later I asked Sir John Tweedy's opinion on the case. He wrote: "There is intense optic neuritis in both as well as the retino-choroiditis, and it is a question whether there may not be some intra-cranial disease as well. There are no present symptoms pointing to intra-cranial disease, and it is difficult to suggest even a probable cause of the inflammation. Syphilis may, I think, be excluded."

A year later active inflammatory signs had subsided, the fundi were thickly set with patches of thinning of the capillary layer of the choroid, some with a little heaping up of pigment at their centres, the majority without. A year later still, "the optic discs look quite normal. R.V.=6/12, L.V.=6/5 partly." The lad was then in good health and engaged in hard manual work.

C.C., a boy, 20 years of age. His right eye was blind, the disc atrophic; some patches of old choroido-retinitis were present on the nasal side of the disc, and a string of them extended down and out from the macula. The left eye at this time appeared normal. Wassermann reaction negative. The choroidal changes in this case diverted my attention from the real lesion; Sir John Herbert Parsons, whose 
assistance I asked, pointed out to me that the boy presented distinct signs of gigantism, and that the optic atrophy in the right eye was most probably the result of pituitary pressure. $\mathrm{He}$ added: "I haven't any idea what the retinal changes mean-they don't look specific."

Eighteen months later the left eye showed a characteristic indentation of the upper temporal field (see chart below) and the outer half of its fundus was pretty thickly covered by patches of superficial atrophy of the choroid.

In November, 1921, the patient had a pituitary tumour removed by Mr. Sargent; in Queen Square Hospital. The operation was most

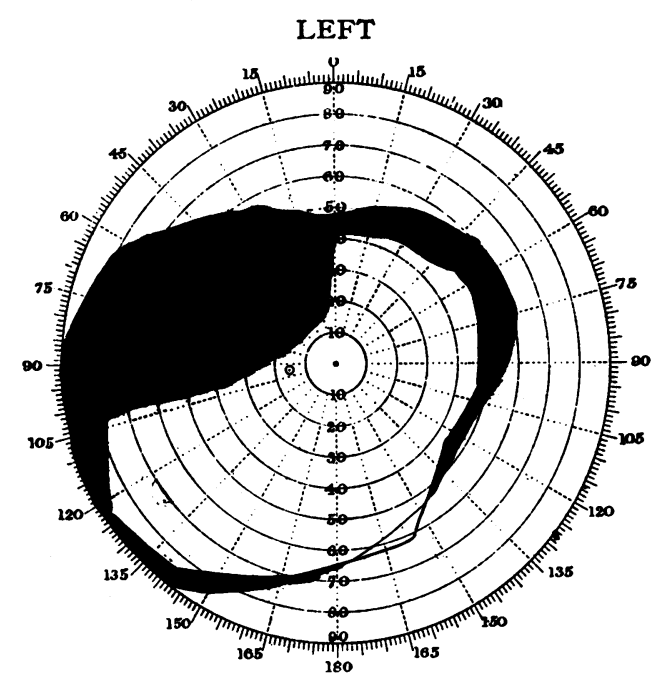

successful; the boy is now in good health, earning his living, and the eye changes appear to be completely arrested.

Baby J. I have under observation at the moment a male child, aged 6 months, with extensive disorganisation of choroid and retina and vitreous opacities, in whom the only other discoverable lesion is an obviously abnormal overgrowth and adiposity of the whole body. The X-ray plate, however,shows no enlargement of the pituitaryfossa.

K. R. T., a girl aged 15 years. Seen December 21, 1923, for recent failure of sight. Right vision $<6 / 60$, left $6 / 36$ (with correction). Optic discs very hazy and perhaps a little swollen, retinal veins rather full. Scattered over both fundi were numerous patches of superficial atrophy of the choroid, many without pigment, others with a little heap of pigment towards the centre. The patches were irregular in shape, sub-angular, with a tendency to run together in trailing groups. Fields of vision as shown on opposite page.

Mr. Leslie Paton kindly saw this case for me. He wrote: "I think the ocular changes are mainly due to the primary choroiditis, 
i.e., the retinitis and papillitis are secondary to the very extensive disseminated choroiditis. With regard to the fields I find a very definite small relative scotoma in each eye just below the fixation point, but I think that is due to the macular choroidal inflammation."

He also mentioned that he had recently seen a somewhat similar case in which thorough examination gave no clue at all to the causation.

This also proved to be the case with K. R. T. The Wassermann reaction was negative, tuberculin reaction negative, urine normal and free from pathogenic bacilli.

Her condition is improving, the discs being less hazy, and central vision having risen to $6 / 12$ in each eye. The fields of vision are now normal.
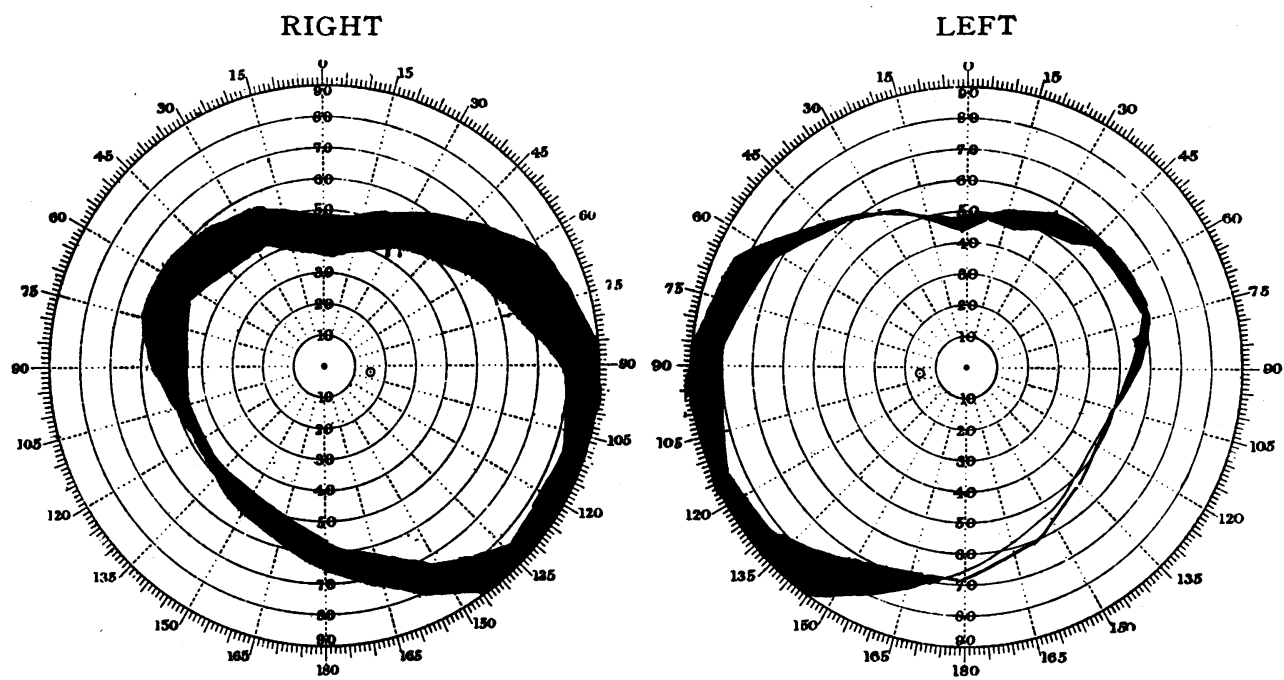

All these cases, except the pregnancy case and C.C., were given mercury. It is difficult to say whether it had any influence on the disease ; it certainly did not prevent an attack developing in the second eye in those cases in which the onset was not simultaneous.

The cases are very incomplete; I regret especially that in the earlier ones the visual fields were not taken; but even as they stand they seem to show that disturbance of pituitary function is a possible cause of well-marked retino-choroidal inflammation. And I suggest that, in the absence of any other obvious causative agent, the form of retino-choroiditis described in the first case may be the result of a transitory pituitary dysfunction. It seems to occur in adolescents or young adults, and to be characterized by an acute onset, with much inflammatory change in the optic nerve head and retina, wide-spread but always superficial and therefore I think possibly secondary lesions of the choroid, a self-limited course, and recovery with relatively good vision. 